\title{
A TRAJETÓRIA FORMATIVA DO EDUCADOR DE HISTÓRIA NA ESCOLA PÚBLICA
}

\begin{abstract}
Mychelyne Barros Costa Ferreira*
Resumo: O magistério na Rede Municipal do Rio de Janeiro é o cenário do liame autoral. Embasada por uma pesquisa teórica, a prática educativa reflexiva dos autores encaminhou esta proposta de estudo cujo enfoque é o professor que se entende como educador com o propósito formativo e a maneira como concretiza sua prática em seu cotidiano escolar. A hipótese que constitui o eixo dessa reflexão propugna o educadorem cuja prática predomina a preocupação com um ensino de História que privilegia a formação de valores, atitudes, procedimentos perante o contexto sociopolítico e cultural. Nesse tocante, analisa-se a formação e as práticas pedagógicas dos profissionais de Educação em História, os quais exercem sua função nas séries finais do Ensino Fundamental enquanto educadores.

Palavras-chave: Educador de História. Formação pedagógica. Prática pedagógica.
\end{abstract}

\section{LA TRAYECTORIA FORMATIVA DEL EDUCADOR DE HISTORIA EN EL COLEGIO PÚBLICO}

Resumen: El magisterio en la Red. Municipal de Río de Janeiro es el escenario de la cadena autoral. Teniendo como base una investigación teórica, la práctica reflexiva de los autores desarrolló la propuesta de estudio cuyo enfoque está en el profesor que se entiende como educador con el propósito formativo y la manera como concreta su práctica en su cotidiano escolar. La principal hipótesis propugna al educador en cuya práctica predomina la preocupación con una enseñanza de Historia que privilegia la formación de valores, actitudes, procedimientos ante el contexto sociopolítico y cultural. En este enfoque, se analiza la formación y las prácticas pedagógicas de los profesionales de Educación en Historia, los cuales ejercen su función en los años finales de la Enseñanza Fundamental como educadores.

Palabras-clave: Educador de historia. Formación pedagógica. Práctica pedagógica.

Submissão 09 - 10-18 Aceite 13- 10-18

\section{INTRODUÇÃO}

Toda pesquisa (...) se articula com um lugar de produção socioeconômico, político e cultural. Implica um meio de elaboração que circunscrito por determinações próprias: uma profissão liberal, um posto de observação ou ensino, uma categoria de letrados, etc. Ela está, pois, submetida a imposições, ligada a privilégios, enraizada em uma particularidade. É em função deste lugar que se instauram os métodos, que se delineia uma topografia de interesses, que os documentos e as questões, que lhes serão propostas, se organizam. (CERTEAU, MICHEL, 2008, pp. 66 e 67).

Desde, pelo menos, o clássico texto de Michel de Certeau (2008), o lugar de fala dos autores tornou-se indispensável para qualquer discussão. No caso concreto do artigo que aqui se apresenta, este aspecto é, em si, a própria essência do texto, sem o qual, todo e qualquer argumento subsequente perde o sentido. $O$ exercício do

\footnotetext{
* Possui graduação em História pela Universidade do Estado do Rio de Janeiro (2002) e mestrado em História pela Universidade do Estado do Rio de Janeiro (2005). Em 2012, concluiu o doutorado em Educação pela Universidade do Estado do Rio de Janeiro. Desde 2002, trabalha como professora de História. Atualmente, integra o corpo docente da Secretaria Municipal de Educação da Cidade do Rio de Janeiro. Tem experiência na área de Educação com ênfase em ensino de História. Dentre os temas desenvolvidos, ao longo da trajetória acadêmica e profissional, destacam-se: Ética, Educação e Valores; Juventudes; Cultura; Culturas Juvenis; Relações Culturais; Política Cultural.
} 
magistério na Rede Municipal do Rio de Janeiro, em unidade escolar localizada na zona norte da cidade, é o elemento que une os autores e contribui para vivências convergentes no ofício docente. O resultado das múltiplas experiências vividas ao longo dessas trajetórias profissionais fomentou os questionamentos, que ora constituem o objeto de análise desse texto: a formação e as práticas pedagógicas dos profissionais de Educação em História, os quais exercem sua função nas séries finais do Ensino Fundamental enquanto educadores e os obstáculos com os quais se deparam na realidade cotidiana da sala de aula.

Parece-nos relevante destacar o fato de ambos os autores terem realizado sua formação inicial na mesma universidade, porém com uma década de diferença entre eles. Esse hiato temporal favoreceu o debate de ideias e a multiplicidade de visões, nem sempre concordantes, acerca do papel e da importância desta formação na prática efetiva do exercício docente.

Inicialmente, faz-se mister esclarecer o uso do termo educadorem distinção ao professor. Nesse aspecto, propugnamos a acepção de educador àqueles profissionais de Educação em História em cujasatividades de ensino perpassam a preocupação e o compromisso com a formação de atitudes e valores nos alunos em face do mundo que os rodeia. E, para tal, reconhecemos a importância do docente desenvolver seu trabalho norteado pelo princípio do 'aprender a conhecer'(DELORS, 2006), em que objetiva ensinar os alunos a buscar e utilizar os instrumentos do conhecimento.

Em contrapartida, a escolha por não empregar o termo professor, muito embora não sejam vocábulos diametralmente opostos, justifica-se em razão da pluralidade de concepções: quanto à formação e função dos profissionais de Educação em História, à vertente historiográfica para o ensino da História e à existência de uma diferenciação entre educadores e professores propalada nos Parâmetros Curriculares Nacionais do Ensino Fundamental, a saber:

(...) É no dia-a-dia das escolas e das salas de aula, a partir das condições, contradições e recursos inerentes à realidade local e educacional, que são construídos os currículos reais. São grupos de professores e alunos, de pais e educadores, em contextos sociais e educacionais concretos e peculiares, que formulam e colocam em prática as propostas de ensino. Estes parâmetros oferecem mais um instrumento de trabalho para o cotidiano escolar. (PARÂMETROS CURRICULARES NACIONAIS: HISTÓRIA, 1998, p. 15) 
Em “As Competências Para Ensinar no Século XXI” (PERRENOUD, 2002), observamos a correspondência entre a formação e o papel docente com o modelo de sociedade e de ser humano defendido,o que permite a inferência de uma polissemia do ser professor.De fato, se fizermos um retrospecto da história da educação brasileira, encontraremos distintos significados para oser professore a prática docenteem consonância com as correntes teóricas predominantes de cada período. No livro "Escola e Democracia" (SAVIANI, 1984), em que há uma análise sobre o pensamento pedagógico latino-americano das últimas décadas, encontramos referência da articulação entre a denominada tendência pedagógica e o papel docente: na corrente Tradicional, o docente desempenhava o papel de transmissor inquestionável do conhecimento; na Escola Nova, era um auxiliar do desenvolvimento livre e espontâneo do aluno; na Tecnicista, um administrador das condições de transmissão de conteúdos; na Críticoreprodutivista, destacava-se como orientador; e na Pedagogia Histórico-Crítica, atuava como mediador das trocas de conhecimento. No livro, "Democratização da Escola Pública",Libâneo (1985) corrobora a premissa anterior ao demonstrar a mesma articulação entre corrente pedagógica e função docente.

Da mesma forma, atualmente, a abordagem sobre o papel do profissional de Educação sofre as influências das escolhas ideológicas, ou dos recortes analíticos impressos pelo pensador. Há vozes que defendem o resgate e o reforço do papel de construtor da cidadania (GADOTTI, 2006); outros focalizam o aspecto do sujeito do conhecimento histórico em detrimento da figura de vulgarizador ou transmissor do conhecimento (ROCHA, 2002); a responsabilidade como autor das estratégias de aprendizagens, dos dilemas a serem explorados em sala de aula (RICCI, 2003) e ainda, o caráter determinante na formação de atitudes - positivas ou negativas - perante o estudo (DELORS, 2006).

A temática da formação do profissional de Educação em História se constitui em um campo de grandes disputas teóricas e políticas, envolvendo questões como: 1- a crítica ao paradigma aplicacionista, no qual se verifica uma primazia do conhecimento histórico e uma atribuição de complementaridade ao conhecimento pedagógico na formação inicial; 2- a formação continuada; 3- a defesa da profissionalização do docente em um cenário onde as diretrizes curriculares do curso de História valorizam a formação do historiador em menos-valia ao docente de História (FONSECA, 2003).

No terreno do docente de História existe uma sociedade pluralista discordante quanto à concepção de História que deve ser ensinada e quanto aos objetivos e valores 
que a escola deve fomentar, de modo que é possível encontrar dificuldade na elaboração de uma proposta de ensino em História, mesmo em uma única unidade escolar, dada a diversidade de concepções.

Nesse panorama, salientamos o emprego do termo educador de História focalizando o docente da sala de aula. Outrossim, não propomos uma sistemática oposição entre o conceito de professor e educador. Todavia, pretendemos demarcar nosso campo de observação através da hipótese que constitui o eixo da nossa reflexão: o educadorem cuja prática predomina a preocupação com a contextualização da vida do aluno por meio de um ensino de História que o localize no tempo e no espaço como sujeito através da formação de valores, atitudes, procedimentos perante o contexto social, político, econômico e cultural.

Consignamos a noção de educador tendo em vista um ser e fazer docentes marcados por:

(...) uma nova relação com quem está aprendendo, passar do papel de 'solista' ao de 'acompanhante', tornando-se não mais alguém que transmite conhecimentos, mas aquele que ajuda os seus alunos a encontrar, organizar e gerir o saber, guiando mas não modelando os espíritos, e demonstrando grande firmeza quanto aos valores fundamentais que devem orientar toda a vida. (DELORS, JACQUES, 2006, p.155)

A esse propósito, recomenda-se a integração da dimensão afetiva no exercício da docência como forma de aproximação entre aluno e docente, mas, sobretudo, para que o docente esteja situado diante do contexto físico, social e cultural do aluno, possibilitando a promoção da 'aprendizagem significativa'. Do mesmo modo, preconiza-se a consideração sobre o desenvolvimento do comportamento ético e a orientação aos alunos em valores e atitudes em relação à vida, ao ambiente, às relações humanas e a si próprios (LIBÂNEO, 2004).

(...) pairam sobre os educadores as ameaças de um relativismo ético que pode comprometer o papel educativo do ensino que, no final das contas, consiste em aliar conhecimentos a convicções, considerando estas como princípios norteadores da personalidade diante de problemas e dilemas da vida prática. A formação de atitudes e valores, perpassando as atividades do ensino, adquire, portanto um peso substantivo na educação escolar, porque se a escola silencia sobre valores, abre espaço para os valores dominantes no âmbito social. As escolas devem, então assumir que precisam ensinar valores. Certamente, a todo o momento a escola, os professores, o ambiente passam valores como parte do chamado currículo oculto (...). (LIBÂNEO, JOSÉ CARLOS, 2004, p.45). 
Sendo assim, a apreensão do educador incorporada à presente análise concebe um profissional de Educação em História cuja prática pedagógica esteja nucleada pelo propósito formativo dos alunos. A partir do 'ser e fazer docentes' regidos por uma concepção de Educação e da própria História como disciplina escolar em que pese à formação de uma maneira de ver e compreender o mundo (FONSECA, 2003).

É importante enfatizar que a prática docente pode ser realizada sem que haja uma valorização do seu caráter formativo, ou seja, é possível apenas transmitir conhecimentos completamente alheios aos interesses e à compreensão do aluno, exercer uma prática repetitiva e mecânica. Nesta medida, o ser educador contempla uma escolha pessoal e profissional cultivada por diferentes visões teóricas, políticas e religiosas (FONSECA, 2003).

Acreditamos que o ser educador é fruto de um posicionamento e uma reflexão que o sujeito-professor faz ao longo de seu julgamento a respeito de sua própria formação, trajetória profissional e concepção do seu ofício. Nesse escopo, tencionamos examinar/problematizar a trajetória do professor que se entende como educador com o propósito de desvelar o processo formativo e a maneira como concretiza sua prática em seu cotidiano. Cabe reiterar que o uso do termo educador em vez de 'professor' tem por justificativa a intenção de sublinhar a preocupação do docente em não ser "transmissor de conhecimentos", ao contrário, haja um objetivo intrínseco e permanente no seu "fazer" de dialogar com a realidade do aluno, ensinando conteúdos de maneira a suscitar um posicionamento crítico, no qual o aluno possa desenvolver sua capacidade valorativa, reflexiva, diante da sociedade e de si mesmo.

\section{QUESTÕES SOBRE A FORMAÇÃO PARA A DOCÊNCIA}

A formação do profissional de História é um tema controvertido, por exemplo, em virtude dos embates existentes entre os organismos oficiais e a associação de professores quanto à estrutura curricular e o processo formativo do profissional de Educação durante o curso de graduação em História.

A Associação Nacional pela Formação dos Profissionais da Educação (ANFOPE)formula uma política nacional para a profissionalização do magistério pautada pela relação entre teoria e prática, ensino e pesquisa, conteúdo específico e conteúdo pedagógico, de modo a atender a natureza e a especificidade do trabalho educativo. Não obstante às mudanças deliberadas quanto à definição do perfil do 
formando nos cursos de graduação (RESOLUÇÃO CNE/CES 13/2002), o profissional de Educação em História vivencia seu processo formativo em meio a uma dicotomia: "teoria / prática, com a desarticulação entre a preparação em História e a preparação pedagógica e com a separação ensino/pesquisa existentes no interior dos próprios cursos de licenciatura e entre licenciaturas e bacharelados". (FONSECA, SELVA, 2003, p.73) Entretanto, cabe ressalvar que a formação docente é um tema mais abrangente:

\begin{abstract}
"Hoje, pensar a formação docente implica pensar simultaneamente nos vários aspectos que constituem esse processo: formação inicial (cursos de licenciatura), formação contínua (cursos, treinamentos em serviços, assessorias etc.) condições de trabalho (materiais, carga horária, salário) e regulamentação da carreira". (IBIDEM)
\end{abstract}

No tocante à prática docente, concordamos com Libâneo que afirma:

(...) A prática escolar, assim, tem atrás de si condicionantes sociopolíticos que configuram diferentes concepções de homem e da sociedade e, consequentemente, diferentes pressupostos sobre o papel da escola, aprendizagem, ralações professor-aluno, técnicas pedagógicas, etc. Fica claro que o modo como os professores realizam seu trabalho, selecionam e organizam os conteúdos das matérias, ou escolhem técnicas de ensino e avaliação tem a ver com pressupostos teórico-metodológico, explícita ou implicitamente. (LIBÂNEO, JOSÉ CARLOS, 1985, p.19).

A temática do educador de História, segundo a definição já explicitada, constitui uma dimensão relevante para pesquisa no campo educacional, tendo em vista alguns vetores que perpassam este ofício. Por um lado, a finalidade atribuída à disciplina escolar de História assinalada nos Parâmetros Curriculares Nacionais do Ensino Fundamental:

(...) difundir e consolidar identidades no tempo, sejam étnicas, culturais, religiosas, de classes e grupos, de Estado ou Nação. (...) fortalecimento do papel da História na formação social e intelectual de indivíduos para que, de modo consciente e reflexivo, desenvolvam a compreensão de si mesmos, dos outros, da sua inserção em uma sociedade histórica e da responsabilidade de todos atuarem na construção de sociedades mais igualitárias e democráticas. (PARÂMETROS CURRICULARES NACIONAIS: HISTÓRIA, 1998, p. 29)

Por outro, o desafio de “(...) educar as crianças e os jovens, propiciando-lhes um desenvolvimento humano, cultural, científico e tecnológico, de modo que adquiram 
condições para enfrentar as exigências do mundo contemporâneo (...)" (BITTENCOURT, CIRCE, 2004, p.14). Entretanto, apesar do caráter fundamentalmente formativo da História e do seu ensino:

(...) Os professores de história sujeitos do processo vivenciam uma situação extremamente complexa e ambígua: trata-se de uma disciplina que é ao mesmo tempo extremamente valorizada, estratégica para o poder e a sociedade e ao mesmo tempo desvalorizada pelos alunos e por diversos setores do aparato institucional e burocrático. (FONSECA, SELVA, 2003, p. 70).

Não obstante às adversidades, os educadoresseguem o desenvolvimento de seus trabalhos, do compromisso em educar. Nesse sentido, compreendemos essa tarefa com base no conceito da 'educação ao longo de toda a vida', isto é, "uma construção contínua da pessoa humana, do seu saber e das suas aptidões, mas também da sua capacidade de discernir e agir. Deve levá-la a tomar consciência de si própria e do meio que a envolve e a desempenhar o papel social que lhe cabe (...)". (DELORS, JACQUES, 2006, p. 106).

Trata-se de um pressuposto educativo apresentado à UNESCO a partir do relatório produzido pela Comissão Internacional sobre Educação para o século XXI. Entre 1993 e 1996, especialistas do mundo inteiro contribuíram no empreendimento de uma revisão crítica da política educacional de todos os países. Os resultados desse estudo foram publicados na obra "Educação: Um tesouro a descobrir" coordenada por Jacques Delors.

Em acordo a essa perspectiva, encontra-se uma categoria utilizada na investigação, a saber: 'aprender a conhecer'. Uma aprendizagem em que se valoriza:

“(...) não tanto a aquisição de um repertório de saberes codificados, mas antes o domínio dos próprios instrumentos do conhecimento. Trata-se de um meio, porque se pretende que cada um aprenda a compreender o mundo que o rodeia; e finalidade, porque seu fundamento é o prazer de compreender (...)". (DELORS, JACQUES, 2006, p. 90).

Sob a orientação do 'aprender a conhecer', desenvolvemos a noção do educador de História através da seguinte consideração:

(...) $\mathrm{O}$ trabalho docente está impregnado de intencionalidade, pois visa à formação humana por meio de conteúdos e habilidades, de pensamento e ação, implica escolhas, valores, compromissos éticos. Isso significa 
introduzir objetivos de natureza conceitual, procedimental e valorativa, em relação aos conteúdos da matéria que ensina; transformar o saber científico ou tecnológico em conteúdos formativos; selecionar e organizar conteúdos formativos; selecionar e organizar conteúdos de com critérios lógicos e psicológicos, em função das características dos alunos e das finalidades do ensino; utilizar métodos e procedimentos de ensino específicos, inserindoos em uma estrutura organizacional em que participe de decisões e ações coletivas. (BITTENCOURT, CIRCE, 2004, p. 18).

Desse modo, enfocamos a dimensão formativa, bem como a orientação pedagógica, a prática escolar, propriamente dita, realizada pelo educador de História no seu cotidiano.

A análise entre a formação do docente e sua opção consciente por ser educador está embasada pelo viés da valorização do profissional de Educação e por uma compreensão que envolve:

(...) formação inicial e continuada, articulada, identitária e profissional. Essa formação identitária e epistemológica, ou seja, reconhece a docência como um campo de conhecimentos específicos configurados em quatro grandes conjuntos, a saber: 1 - conteúdos das diversas áreas do saber e do ensino, ou seja, das ciências humanas e naturais, da cultura e das artes; 2) conteúdos didático-pedagógicos, diretamente relacionados ao campo da pratica profissional; 3) conteúdos ligados a saberes pedagógicos mais amplos do campo teórico da prática educacional; 4) conteúdos ligados à explicitação do sentido da existência humana individual, com sensibilidade pessoal e social. E essa formação identitária é também profissional, ou seja, a docência constitui um campo específico de intervenção profissional na prática social. (IBIDEM)

A conjuntura contemporânea demanda da escola respostas educativas e metodológicas em relação a novas exigências da formação como a capacitação tecnológica, a diversidade cultural, a alfabetização tecnológica, a superinformação, o relativismo ético, a consciência ecológica. Nesse tocante, “(...). Pensar num sistema de formação de professores supõe, portanto, reavaliar objetivos, conteúdos, métodos, formas de organização do ensino diante da realidade em transformação". (LIBÂNEO, JOSÉ CARLOS, 2004, p. 80).

A prática docente, nesse aspecto, requer do educador uma ampliação de “(...) sua consciência sobre a própria prática, a da sala de aula e a da escola como um todo, o que pressupõe os conhecimentos teóricos e críticos sobre a realidade". (BITTENCOURT, CIRCE, 2004, p. 15). Portanto, o fulcro teórico deste estudo, fundamenta-se na articulação entre: 1- uma concepção de educação ampla e contínua; 2- o objetivo pedagógico referendado por uma aprendizagem da busca do 
conhecimento; 3- a noção de educador baseada em uma escolha pessoal e deliberada do docente de mediar, principalmente, a formação humana e o posicionamento dos seus alunos perante o mundo; 4- a formação desse profissional de Educação orientada pela conjugação entre: teoria e prática, ensino e pesquisa, conteúdo específico e conteúdo pedagógico; 5- a concretização do trabalho docente em uma prática pedagógica coerente com as concepções de homem e da sociedade e, consequentemente, diferentes pressupostos sobre o papel da escola, aprendizagem, ralações professor-aluno, técnicas pedagógicas, etc.

\section{EM QUESTÃO: AS VIVÊNCIAS FORMATIVAS DO EDUCADOR NO COTIDIANO ESCOLAR}

As observações que se seguem ilustram a trajetória formativa, enquanto educadores da área de História, em suas vivências pedagógicas cotidianas compartilhadas em uma unidade de ensino do município do Rio de Janeiro. Mais do que isso, as reflexões que decorrem das indagações propostas, não podem ser compreendidas descoladas do próprio histórico de formação acadêmica de seus autores.

Os cursos de formação de professores, para além das áreas teóricas, algumas das quais bastante tradicionais e consagradas, tem investido fortemente nas chamadas práticas de ensino ou estágios pedagógicos como uma forma de melhor preparar o aspirante à docência ao exercício da prática pedagógica. É desnecessário destacar o papel fundamental que tais estratégias têm no aperfeiçoamento da formação docente, seja no que se refere ao contato do formando com a sala de aula, muitas vezes o primeiro contato fora do papel de aluno, seja na aquisição de alguma forma de vivência no cotidiano escolar mais alargado, para além das quatro paredes da sala de aula.

Dando mais ênfase à parte prática ou à parte teórica, a formação docente parece ainda longe de fornecer ferramentas suficientes para o exercício cotidiano nas salas de aula. Isso não se deve simplesmente a uma inadequação dos currículos formativos, mas principalmente à complexidade das experiências diárias a que professores e alunos são expostos na realidade concreta de suas escolas.

A prática enquanto educador apresenta desafios que só podem ser evidenciados a partir do efetivo exercício em sala de aula. Isso equivale a dizer não ser possível reproduzir em uma ambiente seguro a multiplicidade de variáveis possíveis em uma simples aula de 50 minutos. Neste sentido, é somente no fazer cotidiano, na relação 
com o conhecimento específico a ser trabalhado, nas relações humanas com os alunos e com os colegas de trabalho, na superação de desafios diários, que o professor se realiza, não no sentido da satisfação, mas no sentido de constituir-se como aquilo para o qual se preparou. O formado não é um professor até estar no exercício do magistério. É, portanto, a prática que valida a própria formação.

Como dar conta de um cotidiano escolar marcado por práticas violentas de lado a lado? Como elaborar um planejamento para turmas nas quais professores e alunos parecem não conseguir se conectar? Como realizar projetos dentro de um ambiente em que o respeito mútuo e a paz não estão presentes com frequência? Estas indagações são apenas um pequeno apanhado de exemplos da complexa realidade vivida. Muitas situações expõem um cotidiano pouco convidativo para a relação ensino-aprendizagem ou para relações humanas essenciais a tal prática.

Trata-se de uma situação em que alunos, professores, direção, funcionários, parecem ter perdido a capacidade de dialogar, passando acusar-se mutuamente e a defenderem-se encastelados em seus argumentos ou em suas ações. Exemplos são fartos: Um professor que fala de sua exaustão em função das difíceis condições de trabalho em sala de aula, principalmente no que se refere às relações complexas com os alunos; um aluno que furta o professor em sala de aula; um funcionário que alega não ter mais forças para lidar com a violência dentro da escola; um professor que defende o argumento de que não há nada que se possa fazer para mudar a realidade do aluno e da escola.

Para exemplificarmos de forma mais aprofundada de que maneira essa vivência violenta e insegura impacta nas atividades escolares, podemos apontar um caso concreto. Ainda no início do ano letivo de 2017, em uma turma de $6^{\circ}$ ano, vários objetos dos alunos desapareciam frequentemente. Canetas, borrachas, cadernos e celulares eram furtados, principalmente, mas não exclusivamente, no horário do recreio. As reações a estes eventos eram variadas. Alguns alunos acusavam-se mutuamente, gerando uma tensão constante em sala de aula; outros alunos se ressentiam e se tornavam fechados e pouco abertos à integração com os colegas; um aluno passou a não levar mais material para a escola, alegando que os responsáveis não tinham condições de comprar novas canetas ou cadernos, recusando-se a realizar as atividades; houve, ainda, o caso extremo de duas alunas que nunca mais retornaram à escola, optando pela transferência dentro da rede.

Parece-nos claro que estas práticas influenciam, de maneira negativa e direta, a aprendizagem e as ações dos educadores em sala de aula. Como é possível realizar 
atividades circundados pela desconfiança ou com a presença de alunos que não estão abertos à interação ou, ainda, sem materiais básicos? Esse cenário descrito, com contornos reais, resultava em um ambiente de convivência com professores desmotivados e sem saber como romper com tal ciclo negativo, alunos pouco interessados na aprendizagem e uma escola que se contentava em conter atos de indisciplina e violência em seu interior.

Um dos maiores desafios encontrados na prática efetiva do magistério em uma conjuntura que, aparentemente, não favorece o desenvolvimento esperado das relações afetivas e de construção de conhecimento, localiza-se na tentativa de transformar adversidade em oportunidade. As dificuldades encontradas no cotidiano escolar não podem significar uma sentença definitiva a partir da qual os educadores se encontram amarrados e impedidos de realizar uma atividade docente que atenda às expectativas legais e, mais ainda, às necessidades daqueles envolvidos no processo de ensinoaprendizagem.

Novamente lançando mão de experiências realizadas em nossa unidade escolar, podemos destacar as tentativas de converter as dificuldades encontradas pelos educadores em ações concretas que buscam reverter a situação de insegurança e violência. Seguindo as diretrizes legais e o Projeto Político-Pedagógico da escola, um grupo de educadores se reuniu, ainda em 2016, para desenvolver junto aos alunos, uma peça de teatro que buscava trabalhar as temáticas do preconceito, da violência e do bullying nas escolas municipais. Ainda que este projeto continue em andamento, pois se pretende uma iniciativa permanente e não pontual, podemos apontar essa experiência como obtendo resultados positivos e promissores, não só entre os alunos, mas entre toda a comunidade escolar envolvida, educadores, funcionários, famílias etc. A identificação, por parte dos alunos, com a proposta parece ter surtido o efeito de fazêlos refletir sobre suas práticas e ações. Com isto, não afirmamos que a violência tenha sido suprimida do cotidiano de nossa escola, mas, indubitavelmente, este assunto passou a fazer parte das discussões e debates, trazidos, muitas vezes, pelos próprios alunos. Nos anos subsequentes, a saber, 2017 e 2018, a proposta foi sendo adaptada às realidades da escola, sem perder o contato com os objetivos iniciais. Ainda que hoje não se trabalhe mais diretamente a questão do bullying no projeto de teatro, este tema permanece presente nas montagens apresentadas não como imposição dos educadores, mas como um pedido dos próprios alunos que delas participam.

Outro aspecto importante acerca das atitudes violentas no interior da unidade 
escolar estava ligado à falta de conexão e de identificação com o espaço físico da escola e com a instituição. Depredações, furtos, pichações, são exemplos da maneira como alguns alunos tratavam a estrutura do prédio, vistos pelos professores, muitas vezes, como puro reflexo da sociedade, como consequências de uma desestruturação social que passaria longe do papel social das instituições de ensino. O caminho proposto pela instituição e encabeçado pela área de História foi a construção de um projeto que buscasse resgatar a memória da unidade escolar e da comunidade inserida nela, através de atividades que levassem os alunos a refletir sobre os seus vínculos e de suas famílias com aquele espaço.

Por se tratar de uma instituição com mais de 120 anos e atender às comunidades ao redor há pelo menos meio século - tempo em que a escola está no mesmo prédio que hoje a abriga - o trabalho de resgate do pertencimento à escola foi viabilizado através da interface entre memória e história. $\mathrm{O}$ desarquivamento de documentos com plantas originais das décadas de 1930 e 1940 que retratavam o antigo edifício, imagens de época da região, além dos contatos com ex-alunos e ex-funcionários, possibilitou a gestação, ainda que embrionária, de um sentimento de proximidade dos alunos para com a instituição. Ainda que não tenha sido realizado um levantamento oficial, percebe-se que a maior parte dos alunos desta escola vem de famílias que estudaram naquela mesma instituição, como mães, pais, irmãos, tios, avôs e avós, até mesmo bisavôs e bisavós. Para tanto, organizou-se uma atividade que envolvia toda a escola. As turmas deveriam pesquisar sobre a história daquela instituição e elaborar exposições para que os demais alunos percebessem diferentes aspectos da história da escola e pudessem acessar e construir memórias naquele e daquele espaço.

De todas estas experiências, que não se esgotaram ou findaram, a escola ficou com uma espécie de herança positiva, com murais preservados, grafites idealizados e realizados pelos alunos, que precisa ser constantemente reafirmada, relembrada e retrabalhada. As atividades propostas na unidade estão longe de por fim a comportamentos violentos, destrutivos ou negativos em relação à escola, porém, têm sido pensadas como uma forma de minimizar estas ações, como atividades sobre a história da instituição e importância dela na comunidade em que está inserida; oficinas oferecidas no contraturno como forma de manter os alunos em contato constante com a escola, monitorias de diferentes disciplinas, aulas de reforço etc.

Cabe, ainda, indagarmo-nos sobre o papel específico do educador de História nas práticas aqui apontadas. Parece-nos claro que essas ações poderiam ter sido 
perpetradas por qualquer educador, de qualquer área, o que de fato ocorreu nos casos concretos aqui apresentados. Entretanto, o caráter formativo que a disciplina de História assume na grade curricular escolar, cuja uma das atribuições é a de contribuir para a formação da cidadania e do sentido de pertencimento coletivo e social dos alunos, faz com que o educador de História possa articular os conteúdos e habilidades mobilizados em seus estudos e trabalho, para melhor desenvolver ações e práticas que valorizem a atuação do corpo discente e possam reverter situações de violência em produção de conhecimento.

Neste sentido, é relevante destacar que o processo de formação dos novos educadores, nas academias, precisa levar em conta essa especificidade da prática docente, em especial, ainda que não exclusivamente, na área de História. Faz-se, assim, necessário destacar o exercício de um dos autores como supervisor do Programa Institucional de Bolsas de Iniciação à Docência da Fundação Capes - PIBID - na área de História. Este programa tem por objetivo orientar, preparar, incentivar e estimular jovens formandos da licenciatura em História através de uma inserção intensa e de imersão na prática do exercício docente. Através de observações, atividades, aulas e avaliações, os bolsistas vão construindo um arcabouço prático para a teoria que aprendem nos bancos universitários. Iniciativas como estas, ainda que não sejam capazes de reproduzir sem interferências a prática docente, têm alcançado bons resultados na tentativa de preparação de novos educadores.

O que propomos nas linhas acima é pensar a questão da violência como uma parte integrante e indissociável da realidade de muitas escolas em nossa cidade e, até mesmo, do país. De todas as variáveis que compõem a complexidade da atividade docente, a violência acaba sendo considerada como algo estranho a tal exercício. Talvez aí resida um dos aspectos que se oponham a superação deste problema. Integrar as discussões sobre a violência e tentar reverter esse espinhoso tema em algo produtivo e que envolva os discentes nas discussões parece ser o primeiro passo para a superação, ou pelo menos, para a redução de tal problema.

\section{CONSIDERAÇÕES FINAIS}

A trajetória formativa de um educador é um caminho único engendrado na interface das possibilidades, oportunidades e decisões deliberadas por esse sujeito enquanto segue o seu percurso vivencial. Ao longo do nosso texto, pretendemos ter 
demonstrado a complexidade e relevância acerca da conjuntura necessária durante o período da formação inicial. Pois, o futuro licenciado - inexoravelmente - há de encontrar uma realidade laboral desafiadora. Especialmente, no 'chão da escola pública', evidencia-se amiúde a condição de convivência com dificuldades que sobrepassam os limites da atuação docente. Tal perspectiva realista, contudo, não pretende semear a desmotivação. Ao contrário disso, apresentamos aqui a nossa defesa pelo papel do educador de História tendo em vista o objetivo de construir coletivamente atitudes responsivas positivas em face aos obstáculos do percurso.

Propomos que o exercício docente em parceria com os alunos, através da afetividade e do diálogo, precisa ser encarado como uma oportunidade de transformação de situações difíceis e complexas em trabalhos frutíferos e prósperos. Não apresentamos, entretanto, uma fórmula ou um caminho a ser seguido, mas apenas indagamos e questionamos discursos repetidos de impossibilidade, realçando as potências que alunos e educadores possuem, principalmente, ao trabalharem conjuntamente. Nesse sentido, intentamos ter oferecido uma contribuição para a reflexão de que a escolha por definir-se enquanto educador confere sentido e novas perspectivas à atuação profissional.

\section{REFERÊNCIAS}

ANFOPE. Associação Nacional pela Formação do Profissional de Educação. Disponível em:http://portal.mec.gov.br/cne/arquivos/pdf/Recife.pdf. Acesso em junho de 2017.

BITTENCOURT, Circe Maria Fernandes. Ensinode História: fundamentos e métodos. São Paulo: Cortez, 2004.

BRASIL/MINISTÉRIO DA EDUCAÇÃO. Parâmetros Curriculares Nacionais: História - Brasília: MEC/ SEF, 1998.

CERTEAU, Michel de. A escrita da História $-2^{\text {a }}$ Ed. - Rio de Janeiro: Forense Universitária, 2008.

CONSELHO NACIONAL DE EDUCAÇÃO. Resolução CNE/CES 13/2002. Diário Oficial da União, Brasília, 9 de abril de 2002. Seção 1, p. 33. Disponível em: http://portal.mec.gov.br/cne/arquivos/pdf/CES132002.pdf. Acesso em junho de 2017.

DELORS, Jacques. Educação: um tesouro a descobrir - $10^{\mathrm{a}}$ ed. - São Paulo: Cortez, Brasília, DF: MEC: UNESCO, 2006.

FONSECA, Selva Guimarães. Didática e prática de ensino de história: experiências, reflexões e aprendizados. Campinas, SP: Papirus, 2003.

GADOTTI, Moacir. Pensamento Pedagógico Brasileiro. São Paulo: ed. Ática, 2006. LIBÂNEO, J.C. Democratização da Escola Pública: A Pedagogia crítico-social dos conteúdos. São Paulo: Loyola, 1985. 
Adeus professor, adeus professora? Novas exigências educacionais e profissão docente. $8^{\mathrm{a}}$ ed. - São Paulo: Cortez, 2004.

PERRENOUD, Phillipe. As Competências para ensinar no século XXI.: a Formação dos professores e o desafio da avaliação. Porto Alegre: Artmed, 2002.

RICCI, Claudia Sapag. A formação do Professor e o Ensino de História: espaços e dimensões de práticas educativas. (Belo Horizonte 1980/2003). Tese (Doutorado) Universidade de São Paulo, 2003.

ROCHA, Ubiratan. História, currículo e cotidiano escolar. - São Paulo: Cortez, 2002. SAVIANI, Dermeval. Escola e Democracia. São Paulo: Cortez, 1984. 